\title{
Study Of The Generation Of Microburrs In The Process Of Drilling And Its Subsequent Elimination By Deburring, Of Tubes Cylindrical Aluminum AA6065-T9
}

\author{
Salueña Berna X., Ortiz Marzo J.A, Río Cano C. and Papasseit Borrell R. \\ Grupo de Tecnologia de Fabricación. Dpto. Ingeniería Mecánica, ETSEIAT (UPC) \\ C/ Colom 11, Terrassa (Barcelona) Spain \\ Tel: +34937398713 e-mail: xavier.saluena@upc.edu
}

\begin{abstract}
Creation of microburrs drilling constitute a potencial danger because their detachment can modificate the correct operation of a mechanism. The burrs must be eliminated completely in the case of pistons brake, ensuring a high productivity and a low cost. In this work has been studied the mechanism for the creation of microburrs in thru holes drilled $(\$ 2,02 \mathrm{~mm})$ of a aluminium alloy piston AA6065-T9 in order to various parameters such as the type of drill bit, feedrate, cutting speed and lubrication, imposing a minimum feedrate of $450 \mathrm{~mm} / \mathrm{min}$ not to reduce the current production. Creation of microburrs drilling is inevitable and several deburring processes have been analyzed for their total elimination. After a few first essays, It has been determined that in order that the deburring are effective must be worked with minimal and known position burrr drillings.
\end{abstract}

Keywords: Microburrs, Drilling, Deburring.

PACS: $81.05 .-\mathrm{t}$

\section{CREATION OF MICROBURRS IN THE PROCESS OF DRILLING}

The detachment of the microburrs involves a potencial danger must be avoided in the process of manufacture.

There has been an experimental study on the creation of the burrs in the process of drilled (16 holes) of a piston of a hydraulic system of brake (Fig 1), with the aim of eliminating or minimized the maximum for complete elimination in a later process of deburring.
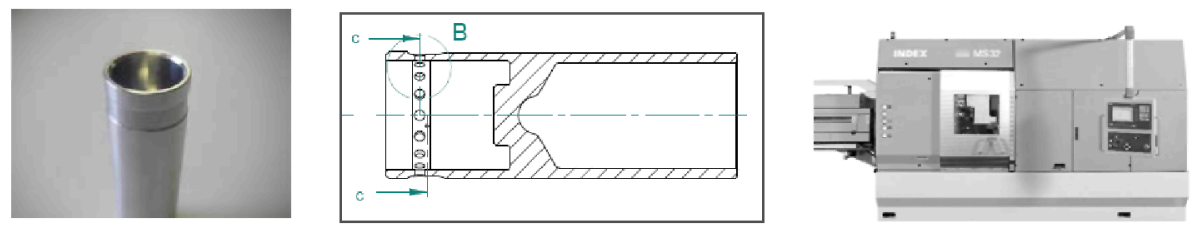

FIGURE 1. Used part and lathe for the experimental study of drilling.

CP1181, Third Manufacturing Engineering Society International Conference edited by V. J. Segui and M. J. Reig

(C) 2009 American Institute of Physics 978-0-7354-0722-0/09/ $\$ 25.00$ 
Drilling has been done in a CNC multitool lathe INDEX MS32P with 6 frontal spindles, two of them with capacity to install motorised tools, and a back spindle. One of the motorised tools installed has been used to realise the drills.

By requirements of the client, the time of the drilled process hasn't to be superior to 15 seconds, what supposes a minimum feed of $450 \mathrm{~mm} / \mathrm{min}$.

\section{Methodology}

It has been realised a study of the microburrs creation for three types of drill tools HSS of two edges, two of them conventionals with differents point angles $(\theta)$, and another bidiametral one. It has been tested for each tool with differents feeds and cutting speed shown in the Table 1.

TABLE 1. Parameters of the assays.

\begin{tabular}{lccc}
\hline \multicolumn{1}{c}{ Drill Tool (two edges) } & $\mathbf{f}[\mathbf{m m} / \mathbf{r e v}]$ & $\mathbf{N}[\mathbf{r p m}]$ & Lubrication \\
\hline Drill A $\left(\theta=120^{\circ}\right)$ & 0,1 & 4500 & 7200rpm (with and \\
Drill B $\left(\theta=150^{\circ}\right)$ & 0,13 & 5500 & without lubrication) the \\
Drill C $($ Bidiametral) & 0,16 & 6500 & rest of cutting speeds \\
$\left(\theta 1=120^{\circ}, \theta 2=60^{\circ}\right)$ & & 7200 & without lubrication \\
\hline
\end{tabular}

Six samples by the combination of study parameter (drill tool, feed, cutting speed and lubrication) have been realised. In the study, the type of burr [1] has been determined by differents ways: measuring the weight of the potential burr, observing its form and considering the length of the real burr [2]. Finally, the results have beeen analyzed to find the optimal parameters to obtain the minim burr.

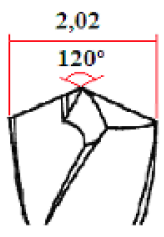

DRILL A

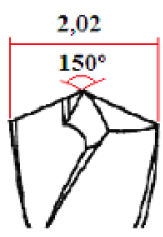

DRILL B

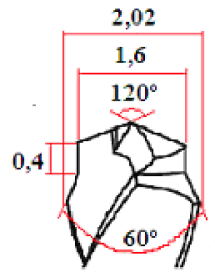

DRILL C

FIGURE 2. Typology of the drill tools (two edges) used in this study.

\section{Theoretical fundamental of the burrs formation}

The mechanism of the burrs formation in drilled already has been defined by several authors ${ }^{[3]}$.

During the process of drilling, the result strength is the combination of the cutting strength, produced in the direction of rotation and the feed one. The cutting strength cuts the material while exists rest material of support. If the feed strength is upper to the resistance exerted by the support material, this yields by plastic deformation and later it's cracked to being dragged by the drill tool in the feed direction. Potential burr is denominated to which it's originated due to this plastic deformation before being 
cut. In many occasions, the drill cuts part of the burr when coming out and the obtained real burr doesn't correspod with the theoretic one, therefore it's important to weigh this cutting burr to know the type of mechanism of burrs formation.

Three types of burrs formation can be defined[1],[3]: uniform burrs (Type I), crown burrs (Type II), burrs by cut (Type III).

Generally, in burrs formation for Type I and Type II (see Fig. 3 and Fig.4), they can appear the following phases: 1) cuts step, 2) beginning of the deformation, 3) development of the deformation, 4) final fracture 5) final burrs formation.

When burr formation is of type III, the phases are different because the drill tool is bidiametral (see Fig. 5). They can appear the following phases: 1) first cut step, 2) burrs formation like type II, 3) second cut step, 4) development of the deformation, 5) final burrs formation.

\section{Type I}

In this type of burr, the layer of material that is deformed plastically in the second phase is very thin (see Fig. 3). This layer cannot be perfored by the central part of the drill tool forming the potential burr. In its exit, the drill tool causes fracture in a burr end that propagates in all their diameter. Finally, the burr get to maintain itself by one of the ends after being pushed and bended or cut by the edge of the drill tool forming a microburr. Generally it happens in low resistance materials.

\section{TYPE I}

1

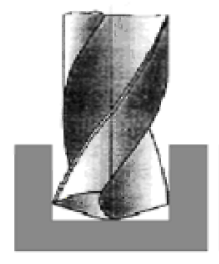

2

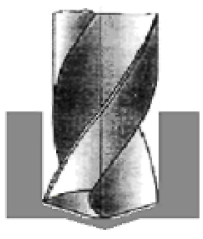

3

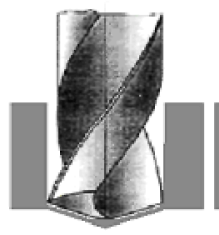

4

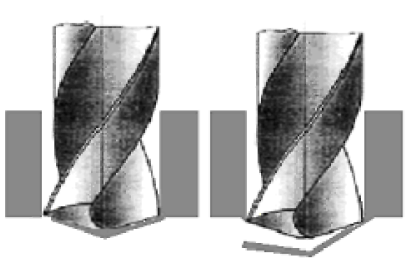

FIGURE 3. Burrs formation of type I

\section{Type II}

In this type of burr, the layer of material that is deformed plastically is thickness and the drill tool still has enough support to continue cutting (see Fig. 4). Due to the feed speed of the tool, the burr is cracked on the central zone. Then the burr bends due to the absence of support of the material. Generally it happens in hight resistance materials. 


\section{TYPE II}

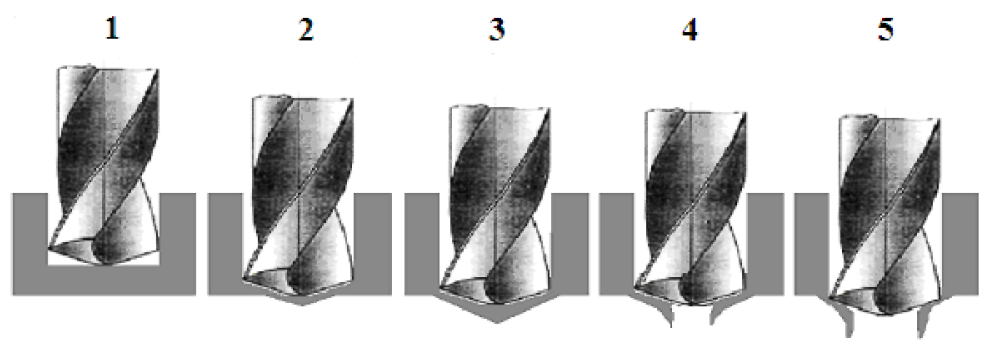

FIGURE 4. Burrs formation of type II

Type III

In this type of burr, the central layer breaks when still there is material of support in the outer perimeter and therefore plastic deformation has not taken place. Then the drill tool continues cutting the material until losing the support and bends the remaining burrs to form microburrs (see Fig. 5).

\section{TYPE III}

1

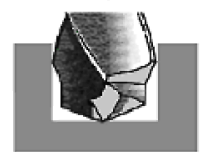

2

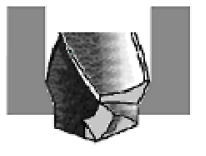

3

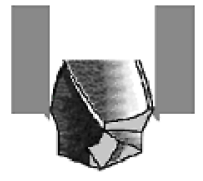

4

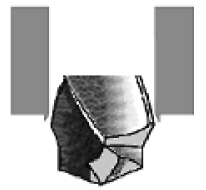

5

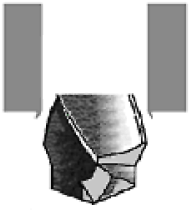

FIGURE 5. Burrs formation of type III

In the drilled process it is not possible to eliminate burrs but it is possible to reduce them to facilitate its elimination in a later process of deburring, therefore one prefers burrs of the type II [4].

\section{Experimental analysis}

The following data have been analyzed in each sample: observation of the type of burr, observation of the length of the real burr (burr adhered to the piece), weight of the potential burr.

For the treatment of the data on the length $(\ell)$ of the burr the results have been grouped at the following way: Group $a(\ell>0,5 \mathrm{~mm})$, Group $b(0,1<\ell<0,5 \mathrm{~mm})$, Group $c(\ell<0,1 \mathrm{~mm})$.

For the treatment of the data on the weigth (p) of the burr the results have been grouped at the following way: Group $a^{\prime}(\mathrm{p}>0,0005 \mathrm{~g})$, Group $b^{\prime}(0,0005 \mathrm{~g}<\mathrm{p})$. 
In this study the burr of type I belongs to group $a^{\prime}$ and type II belongs to group b'.

The procedure of observation and measurement has been the following one:

- Machined and washed of the specimen.

- Drilled with certain tool, feed and cutting speed (with and without lubrication).

- Collection of the potential burr with a special jig.

- Drying with drying paper of the specimen and the potential burr.

- Weighing of the potential burr with a precision machine.

- Visualization and approximated measurement of the real burr with a visual machine or a microscope.

- Analysis of results.
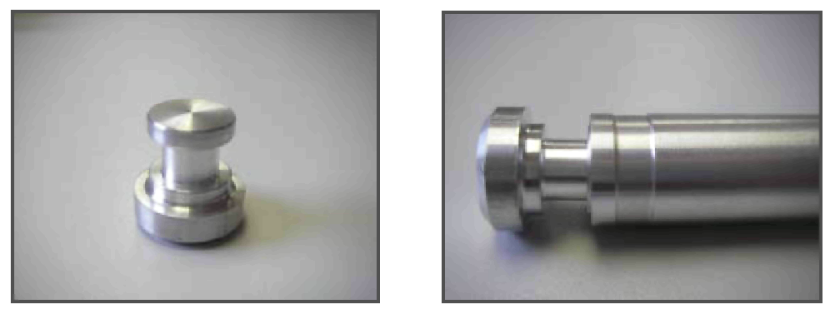

FIGURE 6. Special jig for the collection of the potential burr.

\section{Results}

Based on the obtained results it's possible to be determined that for the studied aluminium alloy, parameters and tools, the generated burrs are of type I and type III.

Generally, for all the studied tools, the length of the burrs reduces when increasing the cutting speed until an optimal point is reached and when reducing the feed (Fig. 7).

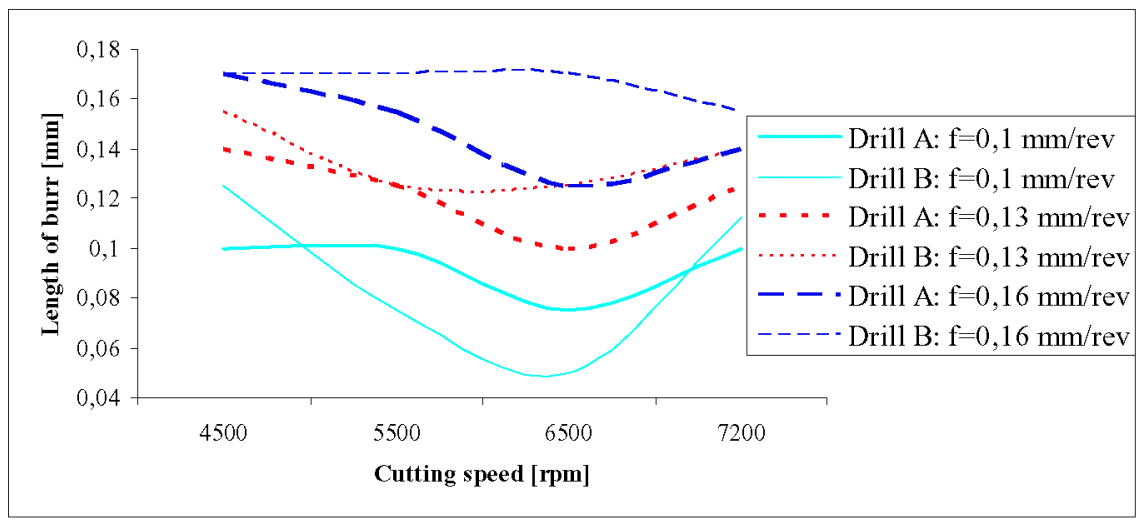

FIGURE 7. Length of burr for drill $\mathrm{A}$ and drill $\mathrm{B}$. 
In the case of the drills A and B, the formed burrs are of type I. This is because the point angles of these drills are great and the material is dragged and embedded by its low resistance to act like a support. For drill B you obtain real burrs lengths and thicknesses of potential burrs greater than with drill $\mathrm{A}$ to high feeds because the point angle is greater.

The burrs done with the drill bidiametral $\mathrm{C}$ are usually of type III, but to high feeds and low revolutions a burrs of type II forms. Theoretically, whichever minor is the point angle $\theta_{2}$ smaller will be the length of the formed burr. Therefore the tools with angles of $60^{\circ}$ have made specifically (see Fig. 2).

In figure 8 one show the rate, for samples of six assays for case, of the length of burrs obtained based on the cutting speed and the feed for differents drills A, B and C.

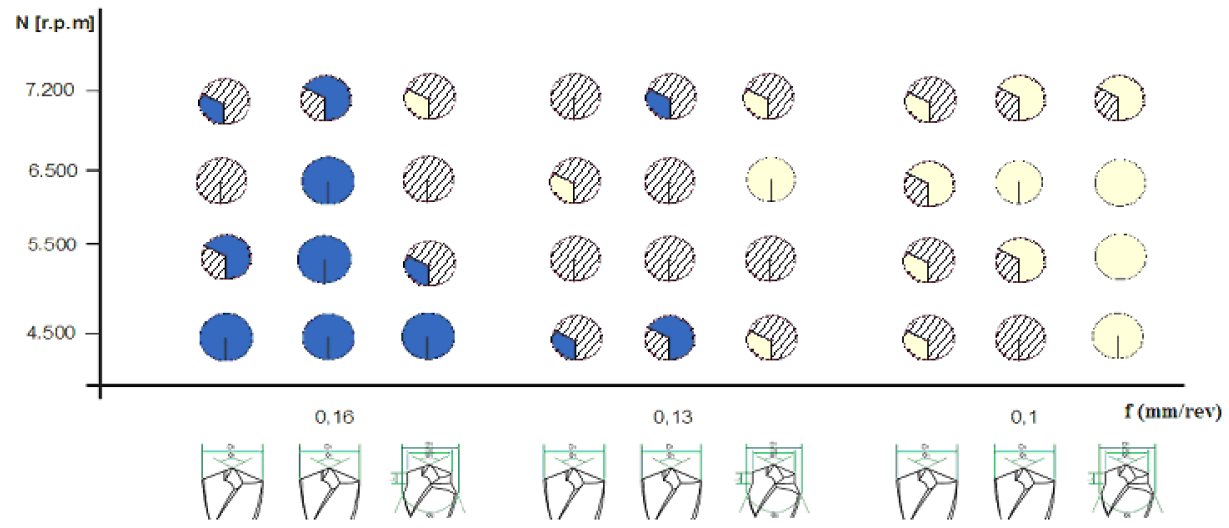

Length of burr $(>0,15 \mathrm{~mm})$

Length of burr $(0,1-0,15 \mathrm{~mm})$

Length of burr $(<0,1 \mathrm{~mm})$

FIGURE 8. Rate of the length of the burr for differents studied parameters.

In figure 8 it is observed as the length of burrs diminishes to low feeds [5]. Also it's recognized that with the drill $\mathrm{C}$ you obtained better results, that is to say, a smaller burr length to average feeds and high revolutions, reason why is possible to secure equal quality with a greater production.

\section{ELIMINATION OF MICROBURRS BY DEBURRING}

After a few first essays, there has decided that in order that the deburring are effective must be worked with minimal and known position burrr drillings[6]. The optimal conditions to secure this type of burr are $\mathrm{N}=6000 \mathrm{rpm}, \mathrm{f}=0,1 \mathrm{~mm} / \mathrm{rev}$ and with a bidiametral drill with point angles $\left(\theta_{1}=120^{\circ}, \theta_{2}=60^{\circ}\right)$.

The burrs must be eliminated completely, ensuring stability, a high productivity and a low cost [7]. 


\section{Methodology}

The analyzed methods of deburring have been classified [8], according to the Table 2 , based on if it is realised in the same lathe where the drilled one is realised or outside this. All the deburring have realised for two cases: realising a slot before drilled (case A) or after drilled (case B) and then deburring. This slot is realised in the inner part of the cylinder, in the drilled zone (see figure 1), and can take advantage to eliminate the burr after the drilled process (case A), although this process causes a new microburr.

TABLE 2. Deburring processes analyzed in the present study.

\begin{tabular}{|l|l|}
\hline Deburring in the same lathe. & Deburring realised in outside machine. \\
\hline Alumina Fiber Rod Type [9] & Electrochemical Machine \\
\hline Milling with Ball Mill & Waterjet Machining \\
\hline Deburring Burr - away [6] & Explosion deburring \\
\hline
\end{tabular}

The Waterjet Machining and Explosion deburring process by their high initial investment and the high thermal conductivity of aluminium have discarded previously.

In all the studied processes, the microburrs appearance has been controlled by means of a vision machine TESA V-300.

They have deburring on the 16 drills of the specimen, having become vision control each 250 specimens (4000 drills) for a maximum sampling of 2000 specimens ( 320000 drills) and being suspended the procedure when the microburr appearance.

\section{Deburring in the same lathe}

He is preferable to deburring in the same lathe which it is drilled because It is avoid intermediate operations between machines. One of the motorized spindle of the lathe has been used to load the deburring tools.

\section{Alúmina Fiber Rod Type}

Tool of the manufacturer Xebec (CH-A12-7M) have been used. These brushes cut the burr by rotation due to the centrifugal force. It has been tested between $6000 \mathrm{rpm}$ and $8000 \mathrm{rpm}$ for the case A and case B.

In the case A we can eliminate the burr working to $8000 \mathrm{rpm}$, but the created chamfer is irregular and great size. In the case B we can eliminate the burr working to $7000 \mathrm{rpm}$ and the created chamfer is regular and small size, but between the drill 44000 and 48000 appears the first burrs due to the wearing of the tool. The changes of tool each 44000 drills reduce the productivity. 


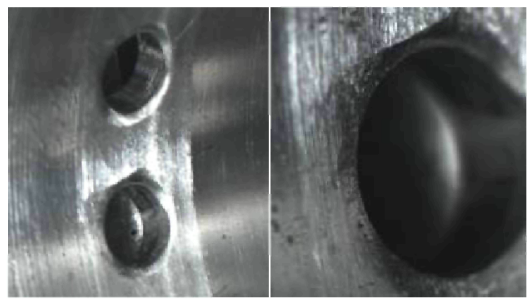

FIGURE 9. Aspect of the hole after deburring in case A.
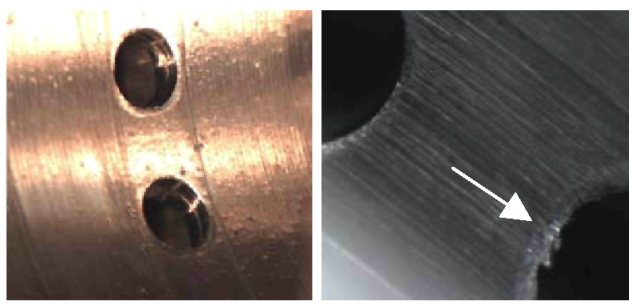

FIGURE 10. Aspect of the hole after deburring in case B. Microburr appear at drill 48000.

\section{Milling With Ball Mill}

It has been used a diameter $6 \mathrm{~mm}$ ball mill at differents cutting speeds and the burr is adhered to the contour in all the cases.

\section{Deburring Burr - Away tool}

It has been used a tool of the manufacturer "Burr - away" type MA. This is an assembly tool with body and cutting edge that operated by one spring (see figure 11).

After the tests realised they have obtained a minimum of 320000 drills without burrs and the reliability and the process time is acceptable ( 18 seconds by piece). The initial cost of implantation of this system is null.
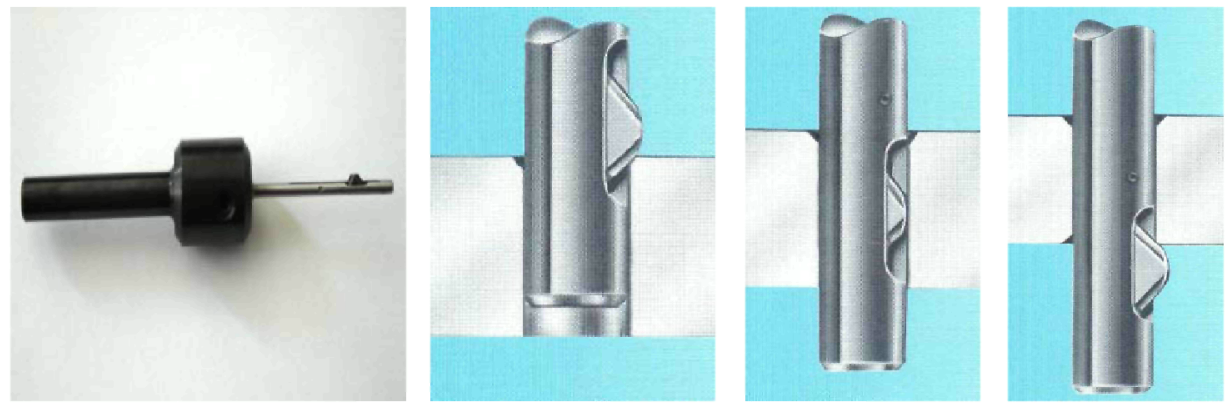

FIGURE 11. Photography and schematic illustration of the deburring process by Burr - Away tool (Source: Burr Away).

\section{Deburring realised outside of the lathe}

The main problem of this type of deburring is the intermediate operations between machines, stocks, parts positioning ... 


\section{Electrochemical Machine}

This method consists of generating an electrical current of high intensity on a concrete zone of the piece and burning burrs by Joule effect. The main problem of this method, besides the high initial investment, is that the associate electrodes can be wear or break by fatigue and that they need to recover, reducing therefore the productivity. The cycle time in a machine in that they can be located up to 6 pieces by cycle is of 2,5 seconds by piece. The reliability is good.

\section{Results}

Of the studied processes of deburring one has determined, based on the reliability and the productivity, that the most recommended are the Burr-away and the Electrochemical machine. The advantages of the Burr-away method are: a null initial investment, drilling and deburring in the same lathe and cost of operation of $0,01 € /$ drill, minor that $0,04 € /$ drill by the other method.

\section{CONCLUSIONS}

It has been determined that in order that the deburring are effective must be worked with minimal and known position burrr drillings[10], this is possible if drilled burrs are of type III and length minor to $0,1 \mathrm{~mm}$.

Generally the length of drilled burrs increased to greater feeds and smaller cutting speeds.

In this study, the drills that with greater reability reduce the length of burr without falling the productivity are the bidiametral ones, because they used generate burrs of type III. The optimal conditions are obtained to the cutting speed of $6500 \mathrm{rpm}$ and the feed of $0,13 \mathrm{~mm} / \mathrm{rev}$, but he is preferable to work at smallers speeds and feeds because it's fulfilled the required productivity and if these parameters are varied slightly the burrs continued under control. The selected parameters are $6000 \mathrm{rpm}$ and $0,1 \mathrm{~mm} / \mathrm{rev}$. In this case, the most recommended deburring process is Burr-away.

\section{REFERENCES}

1. Sangkee Min et all, "Three-dimensional finit element modeling of drilling burr formation. Part II : Burr formation mechanism", Proc. 4th CIRP Int'l Workshop on modeling of Machining Operations, $97-104$ (2001).

2. Kim Won-Sub and Ko Sung-Lim, "Development of Effective Measurement Method for Burr Geometry", Journal of the KSPE. 20-26 (2003).

3. Sung-Lim Koa, Jae-Eun Changa and Gyun-Eui Yangb, "Burr Minimizing Scheme in Drilling", Proceedings of the 6th Asia Pacific Conference on materials Processing. Journal of Material Processing Technology Vol 140, 237-242 (2003).

4. David Dornfeld, "Strategies for Preventing and minimizing Burr Formation", CIRP HPC conference in Aachen, Germany (2004). 
5. Kiha Lee, Boris Stim et all, "Burr formation in micro-machining aluminium, 6061-T6", Ininiatives of precision Engineering at the Beginning of a Millenium. 10th International Conference on Precision Engineering (ICPE), Japan (2004).

6. Kyeong Uk Lee et all, "Development of deburring tool for burrs at intersecting holes", 10th International Conference on Advances in Materials and Processing Technologies, Journal of Materials Processing Technology 454 - 499 (2007).

7. Kim Jinson and David A. Dornfeld, "Cost estimation of drilling operations by drilling burr control chart and bayesian statistics", Journal of manufacturing systems v 20(2), $89-97$ (2001).

8. D.A. Dornfeld, K. Lee et all, "Drilling and deburring in a single process", Proceeding of the institute of mechanical engineers, part B. Journal of Engineering Manufacture v 217 (9), 1327 - 1331 (2003).

9. S. Woods S., Clearing away, Cutting Tool Engineering, 88 - 89 (2005).

10. S. R. Karnik and V. N. Gaitonde, "Development of artificial neural network models to study the effect of process parameters on burr size in drilling", International journal of advanced mamufacturing tecnology $\mathrm{v} 39$ (5), 439-453 (2008). 